“Would it be fair to say that you actively sought out material?" Mitigation and Aggravation in Police Investigative Interviews

Pragmatics and Society 10:1 (due 2019)

Special Issue: Police interviews. Communication challenges and solutions

\title{
Carlos de Pablos-Ortega
}

University of East Anglia

\begin{abstract}
The aim of investigative interviews is to gather comprehensive and reliable information from suspects, offenders, victims and witnesses through questioning. Research on questioning during police interviews has mainly explored question types and question approaches when interviewing adults and children. This paper is concerned with so far unexplored aspects of police interviewing, that is the employment of mitigating and aggravating linguistic devices in questions and statements and their pragmatic effects. The corpus consists of six police interviews with suspects of crime. Mitigation and aggravation strategies were extracted and a total of eighty-two instances were found, analysed and classified into a categorisation taxonomy, which was designed to ascertain the types and functions of mitigation and aggravation devices. The findings reveal that more mitigation than aggravation strategies were used in police questioning and statements during the interviews. Mitigation was found to be used not only as a device for alleviating or attenuating, but also as a strategy to build rapport between suspects and police officers.
\end{abstract}

Key words: mitigation, aggravation, illocutionary force, speech acts, police interviews

\section{Introduction}

In police investigative interviews, obtaining comprehensive, precise and reliable information from suspected offenders, victims of crime and witnesses is the key element of any investigation. Question formulation is the key to ascertaining a detailed account of the facts and helps maintain rapport with suspects (Oxburgh et al. 2010); consequently, appropriate 
questioning needs to balance these two requirements. This will help police elicit as much and as complete and accurate information as possible from the interviewees.

Questions should be phrased clearly in order to avoid possible misinterpretation on the interviewees' part and to maximise the provision of information. Given the power relationship between police officers and suspects, offenders, victims or witnesses of crimes, and the pressure to obtain information, it might be expected that linguistic mitigation devices (such as hedges and indirectness) are avoided in the formulation of questions and statements, whilst face-aggravation strategies (such as directness and imposition) are likely to occur. The latter might be expected to be used to increase the force of questions or the certainty of statements, that is their illocutionary force, in pragmatic terms. The main aim of the present study is to test this expectation and explore the extent to which aggravation and mitigation strategies are actually used in investigative interviews, at the moment of generating questions and summarising the statements of facts provided by interviewees.

So far, research work in police questioning has focused mainly on two areas: questioning techniques during investigative interviews, i.e. the types of questions (open-ended versus closed), and the techniques used in interviews conducted with adults and with children. As Oxburgh et al. (2010: 46) indicate, many studies reveal that interviews tend to be characterised by the frequent use of open questions. This type of question produces longer, more detailed and accurate responses than do closed questions.

Extensive research has established different categorisations for the type of questions used during police interviews (Morris et al. 1965; Fisher, Geiselman, and Raymond 1987; Lamb et al. 1997; Cederborg et al. 2000; Griffiths and Milne 2006; Korkman, Santtila, and Kenneth Sandnabba 2006; Phillips et al. 2012). However, to my knowledge, no previous research has focused specifically on issues of mitigation and aggravation.

This paper firstly presents an explanation of the process of conducting police investigative interviews and the types of questions used. It then looks at elements of questioning from a pragmatic perspective: the speech acts and its types, illocutionary force, and the concepts of mitigation and aggravation. The next section is devoted to exploring mitigation further, looking at its function and at the classification taxonomies of mitigation and aggravation. This is followed by sections comprising the findings and their discussion, while the final section contains the conclusive remarks highlighting the outcome of the investigation.

\section{Police interviews: process and questioning}


The College of Policing website explains that the aim of investigative interviewing is to obtain accurate and reliable accounts from victims, witnesses or suspects about matters under police investigation. However, drawing information is often a challenge, as offenders, victims and witnesses are under pressure in a compromised situation.

According to Oxburgh et al. (2010: 58), there are two main functions when asking questions during police interviews. The first function is to invite or stimulate the interviewee to talking and, consequently, elicit a response. Nevertheless, when the police allow the right of silence to the interviewee, often their best option is to say nothing. The second function of asking questions is to provide statements which can be used later in the prosecution. Suspects are cautioned that, if they decide not to use their right of silence, by responding "no comment" during the interview, and are later charged with the offence and have to answer those questions during the court session, the court may be less willing to believe the answers to those questions are true.

The Association of Chief Police Officers for England and Wales published, in 1992, the first national training programme for interviewing (Griffiths and Milne 2006). This is known as the PEACE ${ }^{1}$ interview model. The model has been developed further and adjusted, taking into account the different stages in the officers' careers and the different types of crimes. The stages have been divided into five tiers. Tier one is designed as an introduction to interviewing for new-officers, whilst tier two is targeted at more experienced officers who need to deal with everyday crimes such as theft or assault. Tier three provides officers with training for dealing with more serious offences; it is divided into three separate sections corresponding to the person being interviewed: a suspect, a witness, or a witness that may vulnerable or intimidated. Tier four deals with monitoring and supervision of the quality of interviews and, finally, tier five introduces the role of the interview co-ordinator for complex and serious crime. (Griffiths and Milne 2006)

\footnotetext{
1 The acronym PEACE stands for Planning and preparation, Engage and explain, Account clarification and challenge, Closure, and Evaluation. Planning and preparing refers to legal and logistical issues. The legal preparation is connected to the interview plan and the subject areas that are going to be covered. The logistical part refers to the preparation of the interview room, the equipment needed and the attendance of other people who need to be present as legally required. Engage and explain is the second part of the PEACE model, and the first phase of the information gathering process. This is the part when the interview process is explained to the suspect. This phase is followed by the account, clarification and challenge phase, where the main aim is to obtain the suspect's account of the incident. When a key aspect is identified, more in-depth probing is carried out. In the event that the information provided shows discrepancies with other evidence, clarification or challenge takes place using that evidence. The closure phase refers to the last stage of the interview; here, the legal requirements are explained; this part of the process includes an explanation for the suspect of what may happen after the interview. The PEACE model concludes with the evaluation phase, which is designed to assess the performance of the interviewer; this provides an opportunity to reflect on future areas of improvement or development in the interview process.
} 
But how is the style of questioning addressed in training? The appropriate formulation of questions is considered a key element for effective interviewing. This information seeking framework (Oxburgh et al. 2010: 57) has been described using the familiar acronym TED: 'Tell, Explain and Describe'. In the guidance interview document for police training (Ministry of Justice, 2011), questions are classified either as open-ended or as specific closed questions. The recommendation is to use open-ended questions during the interview and frame them so that an unrestricted answer is given by the interviewee. Open-ended questions prevent the interviewer from providing their own views of what happened to the suspect, or also prevent any presupposing of information provided by the offender. These questions usually start with "tell me" or "describe".

Conversely, specific closed questions lead to narrow responses. The recommendation is to use them as a follow-up option to obtain information which has not been provided in the free narrative and has not been elicited through the open-ended questions. This group of questions are classified as 'wh-questions': who, what, where, when and why (these question pronouns can also be used to formulate open-ended questions).

The guidance document on interviewing suspects points out that a question beginning with "why" may lead to a response that can create more problems than it solves, as this type of question implies the inclusion of reasons that a witness cannot possibly answer. The question compromises the witness with the response. Besides this, “why' questions also tend to promote the feeling of blame. Victims often partly blame themselves for what happened and so 'why' questions may strengthen this belief. This will not help the suspect or the remembering process.” (Ministry of Justice 2011:79).

Oxburgh et al (2010: 60) point out that there are questions which should be avoided and can be described as inappropriate. These are: leading questions (questions whose aim is to produce a response desired by the interviewer); multiple questions (questions which comprise a sub-set of questions and can lead to confusion); forced-choice questions (questions that offer the respondent a limited number of possible responses, none of which may be the interviewee's preferred answer); and opinion statements (in this case the interviewer reads a statement providing their opinion and expects an answer)

The guidelines used for training do not seem to include information about elements which might strengthen the illocutionary force of questions during interviews. Therefore, it is worth exploring this area and ascertain how certain linguistic elements, and more specifically mitigation and aggravation, might have an impact on the formulation of questions. 


\section{Questioning from a linguistic perspective}

The two main linguistic elements connected with the phenomenon of mitigation and aggravation are speech acts and illocutionary force. Speech acts possess illocutionary force, which is described as the combination of the illocutionary point of an utterance and the particular felicity conditions, which are related to the circumstances and the criteria that must be satisfied for a speech act to achieve its purpose. See Example 1.

(1) Can I ask what that [referring to a USB stick] is used for?

Example 1 has been extracted from the corpus of interviews and illustrates the issue of the illocutionary force of the speech act. During the interview, the officer enquires about the use of a USB stick (what that is used for). However, the question has been phrased using two elements that soften the illocutionary force of the question: the modal verb can, whose main function is to ask for an ability, and the verb ask, which preludes the question. The force of the question would have been stronger if the officer had asked a direct question: what is that used for?

Searle (1976) established a speech act taxonomy that includes five categories: representatives or assertives, commissives, directives, expressives and declarations. His taxonomy presents isolated examples, but when these speech acts are uttered in a specific situation, the boundaries are not always clear. Extralinguistic factors such as the relationship between the interlocutors (social power or social distance) or contextual information, play an important role and are factors that determine the linguistic choice for realising a speech act. As a consequence, the illocutionary force of the utterance might lead to classifying the speech act in a different category.

The ultimate purpose of investigative interviews is to obtain a detailed account of facts concerning the perpetration of a crime and to ratify facts, information and statements. The interviewer tries to get the interviewee to do something (for example, admit having done or seen something), which is, in essence, the realisation of a directive speech act. However, in order to accomplish this objective, the interviewer might make use of a combination of speech acts. He will make statements of facts (assertives) or express a psychological state towards the hearer (an expressive).

One of the extralinguistic factors that play a vital part in the development of the speech act is the power relationship between the interlocutors: police officers and suspects. In police questioning contexts, police officers maintain a position of power towards suspects, and this asymmetrical relationship is a determining factor which needs to be borne in mind when 
analysing the interactions during the interviews. Suspects might feel under pressure because of the authority and power of the interviewer and, as part of the legal requirements, anything that suspects say or declare during the interview process can be used in the event that their case is later taken to court.

\subsection{Speech Acts: Mitigation and Aggravation}

Following Blum-Kulka, House, and Kasper (1989), speech acts comprise three components: head acts, alerters/attention getters and supportive moves. The head act is the part of the utterance which is, in itself, enough to perform the speech act. Alerters, also called attention getters, are opening elements that precede the speech act and are used to get the hearer's attention. Supportive moves are adjuncts to the head act and modify its impact or illocutionary force; they can be placed either before (as pre-supportive moves) or after the head act (as postsupportive moves). Supportive moves can function as mitigators, one of the major elements that is being analysed in the present study.

Mitigation is a pragmatic phenomenon occurring in conjunction with speech acts; it is closely related to the illocution and the illocutionary force of speech acts. The concept has been labelled differently by scholars and researchers. It was first introduced by Lakoff (1973), who called it "hedging" 2 , and originally used it as both an intensifier and de-intensifier of the head act. Based on Lakoff's proposal, Fraser (1975) fully developed the concept as a "hedge performative", used with performative verbs to modify the illocutionary force of the verb.

Similarly, Hübler (1983) established a distinction between "understatements", devices that produce fuzziness within the propositional content, and "hedges", which help reduce the speaker's commitment; subsequently, Holmes (1984) proposed two illocutionary force strategies: boosting and attenuating, which complement one another. Boosters help increase or emphasise the illocutionary force, whilst attenuating devices soften its force. Taking into account politeness phenomena, Brown and Levinson (1987) developed the speech act aspect of hedging; similar to Holmes's proposal, they use hedging to refer to the concepts of upgraders and downgraders. For Brown and Levinson (1987: 61-62), mitigation is connected with the notion of face. Negative face is defined as "the basic claim to territories, personal preserves, rights to non-distraction -- i.e. to freedom of action and freedom from imposition", "the want of every 'competent adult member' that his actions be unimpeded by others". Positive face is

\footnotetext{
${ }^{2}$ For the purpose of this paper, the concepts of mitigation and hedging will be used as synonyms.
} 
“the positive consistent self-image or 'personality' (crucially including the desire that this selfimage be appreciated and approved of) claimed by interactants", "the want of every member that his wants be desirable to at least some others"'.

Mitigation relates to face-threatening acts as it serves as a device to help minimise the imposition of the utterance. At the same time, by being used to avoid or reduce the responsibility of the speaker, it aims at protecting the hearer. (Caffi 2007: 92)

Example 2 from the interview extracts helps illustrate the above components of the speech act and the concept of mitigation:

(2) In your own words and your own time, can you tell me why you think you have been arrested?

The central element (why you have been arrested) is the head act, which is introduced by "in your own words and your own time". This acts as an alerter or an attention getter and its main function is to relieve some of the pressure from the interviewee before he/she proceeds to answer. Two supportive moves are found in this example. The first is "can you tell me", which includes the combination of the modal verb "can" (to express ability) and the verb "tell". The second supportive move is "you think", whose aim is to ask for the interviewee's views about the question. These two supportive moves can be regarded as mitigators as they help soften the illocutionary force of the head act.

\subsection{Classification and uses of mitigation}

Given the diverse approaches to mitigation proposed by different scholars, this section presents the types of mitigation and the main purpose of using this device. Various taxonomies for the categorisation of mitigators have been developed. Brown and Levinson's classification (1987: 169-173), is based on the Gricean maxims and includes: quality hedges, which lessen the commitment to the truth of the proposition; quantity hedges, which signal that the information provided is less precise than expected; relevance hedges, which introduce a shift in topic and manner hedges. Holmes's proposal (1984) is based on illocutionary force and distinguishes four categories: 1) prosodic devices (falling and raising intonation, lower voice, etc.); 2) syntactic devices (tag questions, impersonal constructions, etc.); 3) lexical devices; and 4) discourse devices (digression indicators like by the way). Lexical devices are further divided into attenuating devices, focusing on the speaker, attenuating devices focusing on the hearer, and attenuating devices focusing on content or other. 
An extensive list of linguistic devices, both morphological and syntactic, used in the process of hedging has been compiled by Fraser (2010: 22). His list includes: adverbs, adjectives, impersonal pronouns, indirect speech acts, introductory phrases, modal verbs, tag questions and 'if' clauses.

According to Holmes (1984: 348-350), the reasons why a speaker wants to modify the strength of the illocutionary force may include an uncertainty or unwillingness to take responsibility for the validity of the uttered proposition, thereby decreasing the social distance between the interactants and increasing the solidarity of their relationship (their positive face want). Also, for Caffi (2007: 92), mitigation can be used to emphasise elements such as solidarity, immediacy and empathy. However, it can also widen the gap between the interlocutors, their roles and their degrees of power, thus enhancing asymmetry and increasing the emotive distance.

More recently, Thaler (2012: 911) has drawn attention to the fact that the illocutionary force is not determined by only one indicator, but by a cluster of linguistic devices. Each of these devices is classified as a downgrader or an upgrader in comparison to the illocutionary force of a hypothetical speech act not containing that device. The list of modification devices certainly provides an insight into the diversity and complexity of mitigation phenomena and shows how they can affect different features of a speech act. However, it does not explain in which way each of these devices modifies the illocutionary force of the act and how the resulting force can be described.

For Schneider (2010: 225), mitigation is used to reduce the responsibility of the speaker as well as the possible risks and offences entailed by a speech act. It facilitates the management of interpersonal relations during verbal interaction, as it makes an utterance as acceptable as possible to the interlocutor, without the speaker having to give up his/her standpoint. Mitigation expressions are fine-tuning-devices that achieve a compromise between what the speaker wants to say and what the interlocutor is willing to accept.

The discourse effects of hedging are described by Fraser (2010) in terms of: 1) vagueness, when the information one receives from a speaker lacks the expected precision; 2) evasion, when the information one receives from a speaker fails to meet one's expectations; 3 ) equivocation, or the use of a word with more than one meaning, where the intention is to mislead the hearer; and 4) politeness (mainly as negative politeness, in Brown and Levinson's terms), to minimise the threat of the speech act.

Following the presentation in section 5 of the results of the analysis, the diverse proposals with regard to the types of mitigation and their functions will be used (in section 6) to discuss 
the findings. Given the specific contextual elements associated with investigative interviews, some mitigation types will be used more frequently than others and only some of the functions of mitigators will be applicable to this context.

The opposite of mitigation is the phenomenon of aggravation: a linguistic device where the speaker attacks the hearer's face when realising a speech act. Blum-Kulka, House, and Kasper (1989: 204) refer to these devices as upgraders, increasing the compelling force of the speech act. These researchers point out that aggravation of requests is achieved through internal modification. using intensifiers (an element that the speaker uses to over-represent the reality denoted by the proposition), or using expletives (lexical intensifiers that the speaker uses to express negative emotional attitudes). Aggravation is also associated with the phenomenon of impoliteness. Culpeper (2011: 20) refers to aggravation as 'face-attack' or 'face-attacking' and uses these 'attacks' as synonyms of 'face-aggravation'.

\section{Data and analytical approach}

For the corpus analysed in this investigation, we draw on six British police interviews with suspects of crime, which took place between August 2012 and March 2013. The interviews were recorded as part of the standard police procedure and were subsequently digitised, anonymised and transcribed. The interviews are three hours and sixteen minutes long. These data were collected as part of a funded project entitled 'Translation and Communication in Training' (TACIT; see the introduction to this special issue for more information).

The six interviews are connected to minor crimes: suspicion of fraud by false representation in items sold on websites (two interviews), suspicion of indecent exposure (one interview), suspicion of aggravated burglary (one interview) and suspicion of downloading and being in possession of pornographic material.

The questions and statements made during the interviews were extracted and analysed. The instances including mitigation and aggravation devices were first identified, then classified into categories, following the taxonomies explained in section 4. The mitigation and aggravation devices were analysed in relation to the head act of the speech act. Example 3, in the form of a question, shows that the head act of the speech act (is there content on your computer?) is preceded by two aggravating devices whose aim is to attack the hearer's face and boost the illocutionary force of the question: "I'm not asking you how many" and "I'm asking you". 
(3) I'm not asking you how many, I am asking you is there content on your computer that involves sexual activity between two people.

Example 4 shows a type of mitigation (sort of Norwich, sort of what's around), which does not affect the illocutionary force of the head act as such (how well do you know?).

(4) How well do you know sort of Norwich and sort of what's around the outskirts then? The purpose of this type of mitigation is to express uncertainty and vagueness in relation to the specific element of the speech act (Norwich) but it does not affect the illocutionary force of the head act. Therefore, this type of mitigation is not factored into the analysis of the questions and statements carried out for the present investigation.

The mitigation devices found in the interview scripts have been divided into eight categories (Table 1) corresponding to their functions and their illocutionary force. They have also been classified into syntactic and lexical devices following Holmes's taxonomy (1984).

\begin{tabular}{|l|l|}
\hline Illocutionary force & Expression/Device \\
\hline 1. Reporting & You said/You say \\
\hline 2. Hypothesising & Use of modal verb "would" \\
\hline 3. Modifying possibility & Modal verbs ("can"/“could") \\
\hline $\begin{array}{l}\text { 4. Confirming } \\
\text { statements/information }\end{array}$ & Question tags \\
\hline $\begin{array}{l}\text { 5. Judging/Asking for views or } \\
\text { opinion }\end{array}$ & "I think/Did you think?" \\
\hline $\begin{array}{l}\text { 6. Checking understanding } \\
\text { 7. Expressing intention }\end{array}$ & $\begin{array}{l}\text { "Is it fair to say?/Am I right in } \\
\text { saying?" }\end{array}$ \\
\hline 8. Recognising autonomy & "It is entirely up to you". \\
\hline
\end{tabular}

Table 1. Mitigation devices.

The illocutionary force of the first type of mitigation device has been labelled as "reporting" and is used to report the information or the account provided by the offender. In some cases, the corresponding verbs appear in the present tense (You say that you don't know the number for that, You're saying it wasn't big enough to get it into the neck of the bottle) or in the past tense (You said you don't use sales sites). The reporting verbs function as mitigating devices 
that lessen or soften the illocutionary force of the statement of facts which is provided by the suspect.

The second mitigation device is the modal auxiliary verb "would", which helps modify the illocutionary force of the lexical verb and provide hypothetical meaning (So you wouldn't say that you would go on and do www. whatever website?).

The third mitigation strategy refers to the use of modal verbs, such as "can" and "could", which attenuate the strength of lexical verbs (Can you give us that for the benefit of the tape, is there a pin number? Can you talk me through that conversation you had with the person when it has been set up?). As part of this category, one particular case has been found in which the subject of the question is speaker-oriented (Can I ask what that is used for?) and another one including an impersonal form (Could it be that you are not the only person that is being taken advantage of?).

The fourth mitigation category corresponds to a linguistic device employed to check whether something is true; it is also used to ask for agreement. This happens in the form of question tags ( [...] everyone has different thresholds on everything, don't they?, But that is exactly what you did, didn't you?). When analysing question tags in this context, there are two elements that need to be considered: the intonation and the propositional content that the question tag is referring to. Both aspects determine whether the question tag functions as mitigation or as aggravation.

There are two specific structures that are also used to seek confirmation, which do not seem to appear as direct questions tags. One is the use of "Do you understand what I am saying?" and the other, is the expression "okay" for confirmation at the end of the question: "By you wanting it and looking for it someone has got to put it, okay?"

The fifth category refers to the verb "think", which is used as a mitigator with two different purposes: 1) to hypothesise or reach conclusions based on information or gathered evidence (I think you were going on the internet on the computer specifically to search for pornography), and 2) to ask the offender's opinion or views regarding the facts or account of events (Did you think you were doing anything wrong?).

A further, sixth mitigation device is used to check the suspect's understanding by means of two types of structures: "to be fair" (Is that a fair summary of what you said?) and "to be right" (Am I right in saying you are from America, aren't you?).

The illocutionary force of the seventh mitigation strategy is related to the action and intention associated with the formulation of a question. These are structures including the verbs 
"ask" (I just need to ask you why you don't want one?) and "check" (First thing I want to check with you is your bank account).

The final element of the mitigation category is labelled as "recognising autonomy" and it refers to structures that offer the hearer options when responding to questions. An example found in the corpus of this eighth category is the utterance "it is entirely up to you what you're doing, how you answer the questions".

The aggravation strategies included in Table 2 have been divided into four different categories according to their illocutionary force.

\begin{tabular}{|l|l|}
\hline $\begin{array}{c}\text { Illocutionary force } \\
\text { Expressing } \\
\text { disagreement }\end{array}$ & Example \\
\hline $\begin{array}{l}\text { 2. Demanding/Asking } \\
\text { I disagree with you. }\end{array}$ & $\begin{array}{c}\text { Imperative forms (Tell me, Describe to me) } \\
\text { Ask and tell }\end{array}$ \\
\hline $\begin{array}{l}\text { 3. Intensifying } \\
\text { aggravation }\end{array}$ & Question tags \\
\hline 4. Threatening & What I don't want to have to do is [...] \\
\hline
\end{tabular}

Table 2. Aggravation strategies

The first group consists of devices which express disagreement with the hearer's views: "I disagree with you".

The second strategy includes formulae which demand an answer from the offender or ask an explicit question. The demands are targeted at the hearer, but the strategies employed in this category are formulated from the speaker's perspective (I need to know or I'll ask you) or targeted at the hearer (You tell me or You want to tell me). Imperative verb forms are also included as part of this category (Explain to me how we are going to find this folder on your laptop then?).

The third aggravating strategy is the employment of question tags (some of these are also sometimes used as mitigation devices). In the example "But that is what I think and I think that is the truth, isn't it?", the illocutionary force of the question tag is to threaten the hearer's face by referring to the lexical element that it is reinforcing: 'the truth', in this case. As mentioned before, the intonation of the question tag and the propositional content to which it is referring, are important elements for their categorisation as mitigation or aggravating devices.

The fourth and final category includes strategies for threatening the hearer and for adding pressure in order to elicit an answer (What I don't want to have to do is [...]). 
One feature which applies to both mitigation and aggravation strategies and which has been factored into the analysis, is the orientation of these strategies to either the speaker or the hearer. For instance, in "Am I right in saying...?", the mitigation strategy is carried out from the speaker's perspective, whilst in "Can you describe...?", the mitigation of the verb "can" addresses the hearer.

\section{Analysis of results}

This section gathers the results of the analysis of the statements extracted from the police interviews. First, the total number of aggravation and mitigation devices is presented; then the detailed results of both types of devices are introduced, following the taxonomies included in section 4.

The analyses reveal a total of 82 instances, which have been classified into aggravation and mitigation devices. Graph 1 shows a higher number of mitigation (71\%) than aggravation strategies (29\%). This finding indicates that mitigation seems to be the preferred strategy when conducting investigative interviews, rather than aggravation.

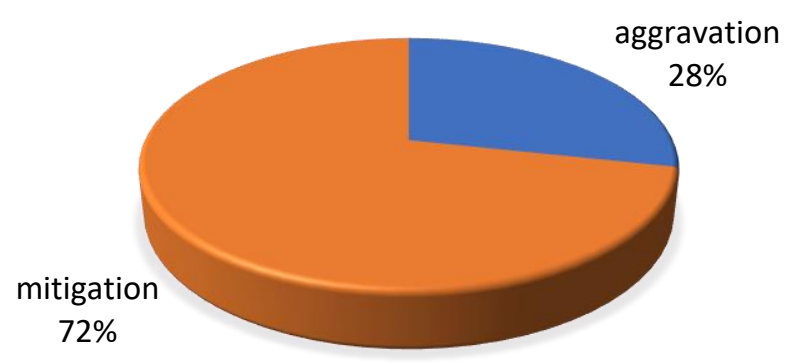

Graph 1. Percentage of mitigation and aggravation devices used in the police interviews

\subsection{Mitigation}

The results obtained for this type of mitigation devices (Graph 2) show homogeneous percentages throughout all categories. However, a slight increase is found in three categories: 
"checking understanding" (expression like to be fair, to be right), "judging and asking for views or opinion" (think) and "hypothesising" (would). Percentages for "expressing intention" (ask and check), for "using modal verbs to modify a possibility" (can and could), "reporting" (say), and for "confirming information/statement" (questions tags) show even figures, thus indicating a homogeneous use of this type of mitigation devices.

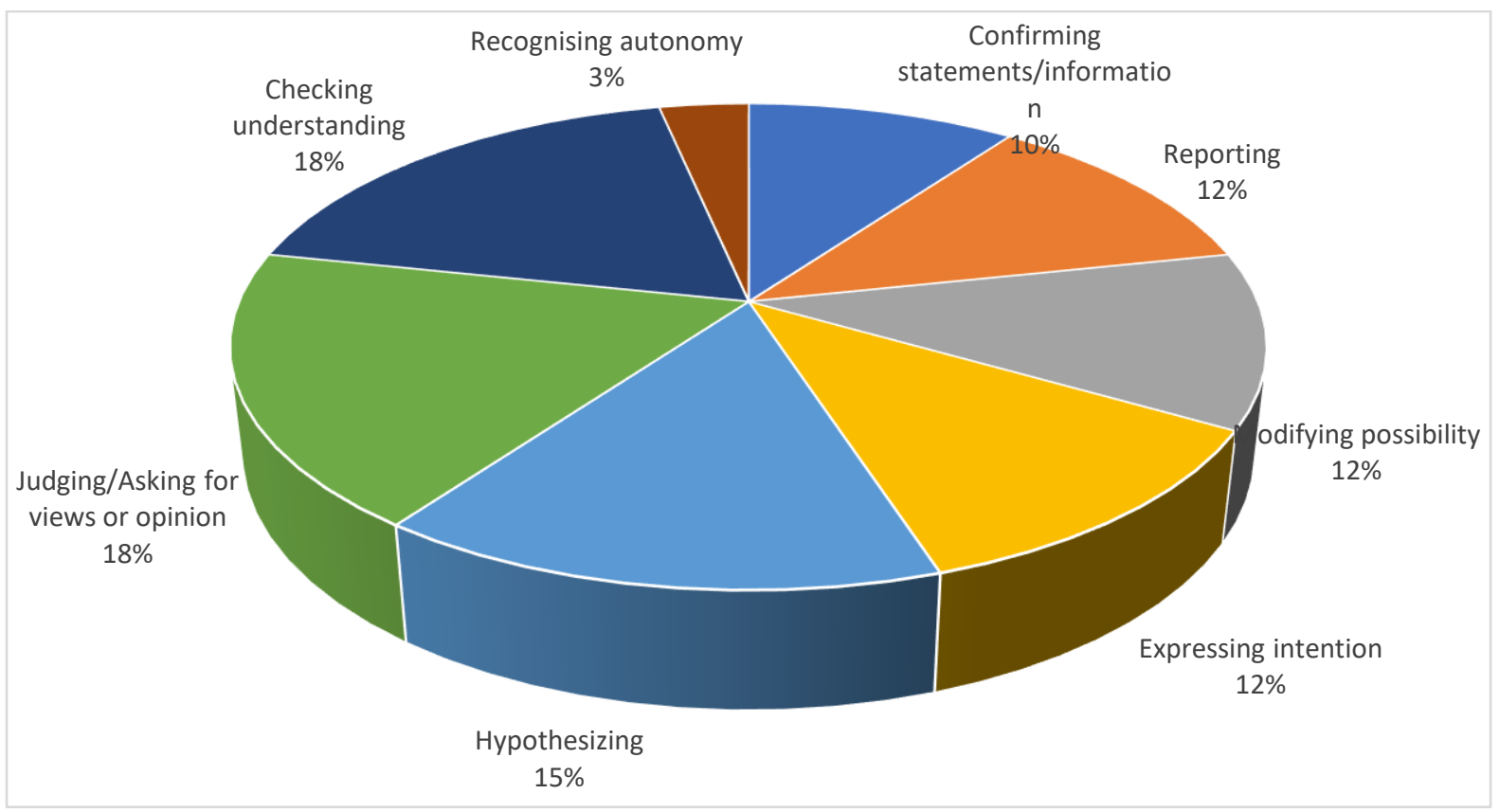

Graph 2. Percentages by type of mitigation devices found in the police interviews

Together with the use of the modal verb would, a different structure is found with regard to the illocutionary force of hypothesising (example 5), namely, a conditional sentence that helps place the offender in a hypothetical situation in the account of events:

(5) So if you had to describe or explain to me or anyone else why you think you have done this?

The results show a combination of two mitigation devices in $25 \%$ of the total number of analysed instances. In principle, the use of more than one device implies further mitigation of the illocutionary force of the head act. Six of the seven categories which are part of the mitigation device taxonomy, present a combination of two strategies. For each of the following categories, one example of these devices has been found: 
- for hypothesising (example 6): the head act (the lexical verb "see") is used with the modal verb "would" in combination with the question tag, added at the end of the statement.

(6) But you would see the title of the movie, wouldn't you? and then click on it a bit like You Tube?

- for reporting (example 7): the verb "say" in the present progressive, alongside a question placed at the end, is used to confirm the statement (is that what you're trying to say?)

(7) You're saying it wasn't big enough to get it into the neck of the bottle, is that what you're trying to say?

- for modifying a possibility (example 8): the modal verb "can" followed by a question tag.

(8) From the images you have seen and the movies you have watched, all the clips you have watched, you can tell me what you have seen on there, can't you?

- for expressing intention (example 9): the verb "ask" introduced by the modal verb "would" for the expression of a hypothesis.

(9) I'd like to ask you a little bit about this Gumtree thing and what has happened and I have heard...

"Checking understanding" is one of the mitigation devices that is combined with others in three different instances. To change the illocutionary force of the verb, in one case, a question tag is used (example 10); the other cases use the modal auxiliary verb "would" (examples 11 and 12).

(10) Am I right in saying you are from America, aren't you?

(11) Would I be right in saying that the popped up in yours was quite clearly not the adult pornography that we would perhaps be used to?

(12) Would it be fair to say that you actively sought out material?

In eight instances, “judging/asking for views or opinion” combines with other categories; question tags (examples 13) and expressions of intention (example 14) have been found in the corpus.

(13) Am I right in saying you are from America, aren't you? 
(14) I think what I'm trying to say is that, in my opinion, it is only my opinion, is that by what you have done you are actively supporting the abuse of children.

Elsewhere, impersonal forms are used to modify the illocutionary force of the head act. Example 15 illustrates how the modal verb "would" is used to express an hypothesis, but it does so impersonally (subject "it"). The intention of this structure is to avoid responsibility and an expression of judgement, such that the police officer does not get involved in the phrasing of the question.

(15) Would it be fair to say that you actively sought out material?

The analysis showed the orientation of the mitigation devices (Graph 3) as being either speakeroriented, hearer-oriented, or impersonal. A high number of hearer-oriented strategies $(71 \%)$ was followed by (22\%) for speaker-oriented devices and a small (7\%) amount of impersonal forms. Given that the questions are formulated for the interrogation of suspects, these results confirm that their main orientation is towards the hearers.

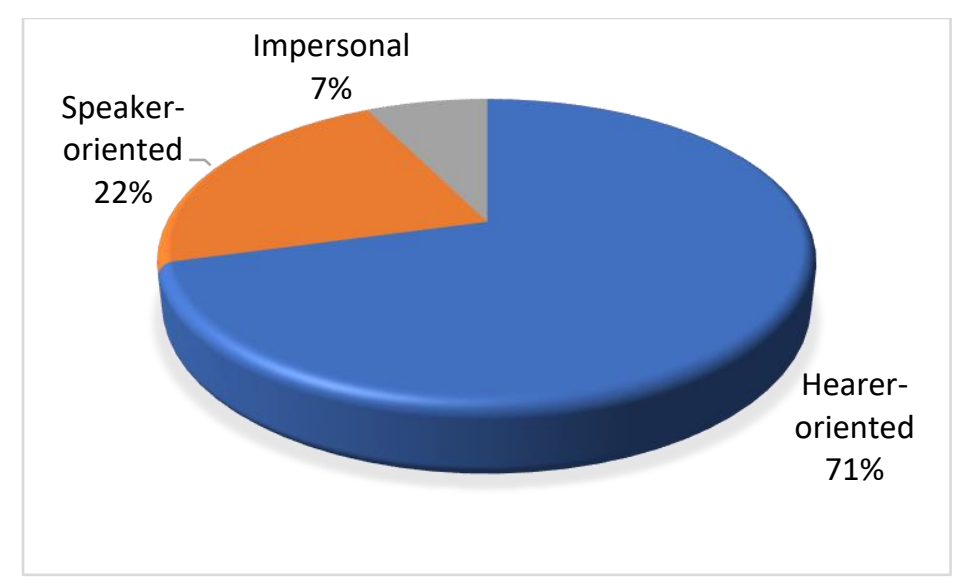

Graph 3. Percentage of device types from the police interviews according to orientation (speaker, hearer, or impersonal)

Despite the small percentage of speaker-oriented devices, the use of these strategies contributes in some cases to the increase of the illocutionary force of the head acts in the formulation of questions and the issue of statements. Example 16 shows how the use of speaker-oriented strategies (I think I would be right) provides a stronger emphasis on the statement when combined with an expression of the police officer's personal view. 
(16) I think I would be right in saying that most adults such as ourselves would not be hugely offended by adult pornography.

Only a few impersonal forms have been found. In example 17, this mitigation device (would it be fair), not being targeted at either the hearer or the speaker, is used to refer to the fairness of the statement or summary of the account provided by the offender. Another impersonal structure, in example 18, shows a modal verb (could), thus providing a hypothetical slant to the question.

(17) So would it be fair to say that you wholeheartly [sic] agree that it is wrong?

(18) Could it be that you are not the only person that is being taken advantage of?

\subsection{Aggravation}

The results show aggravation devices such as "demanding/asking strategies" (imperative verbs, verbs "ask" and "tell") as having the highest percentage of instances (52\%), followed by "threatening devices" (10\%), and by expressing disagreement and passing on responsibility (7\%). See Graph 4.

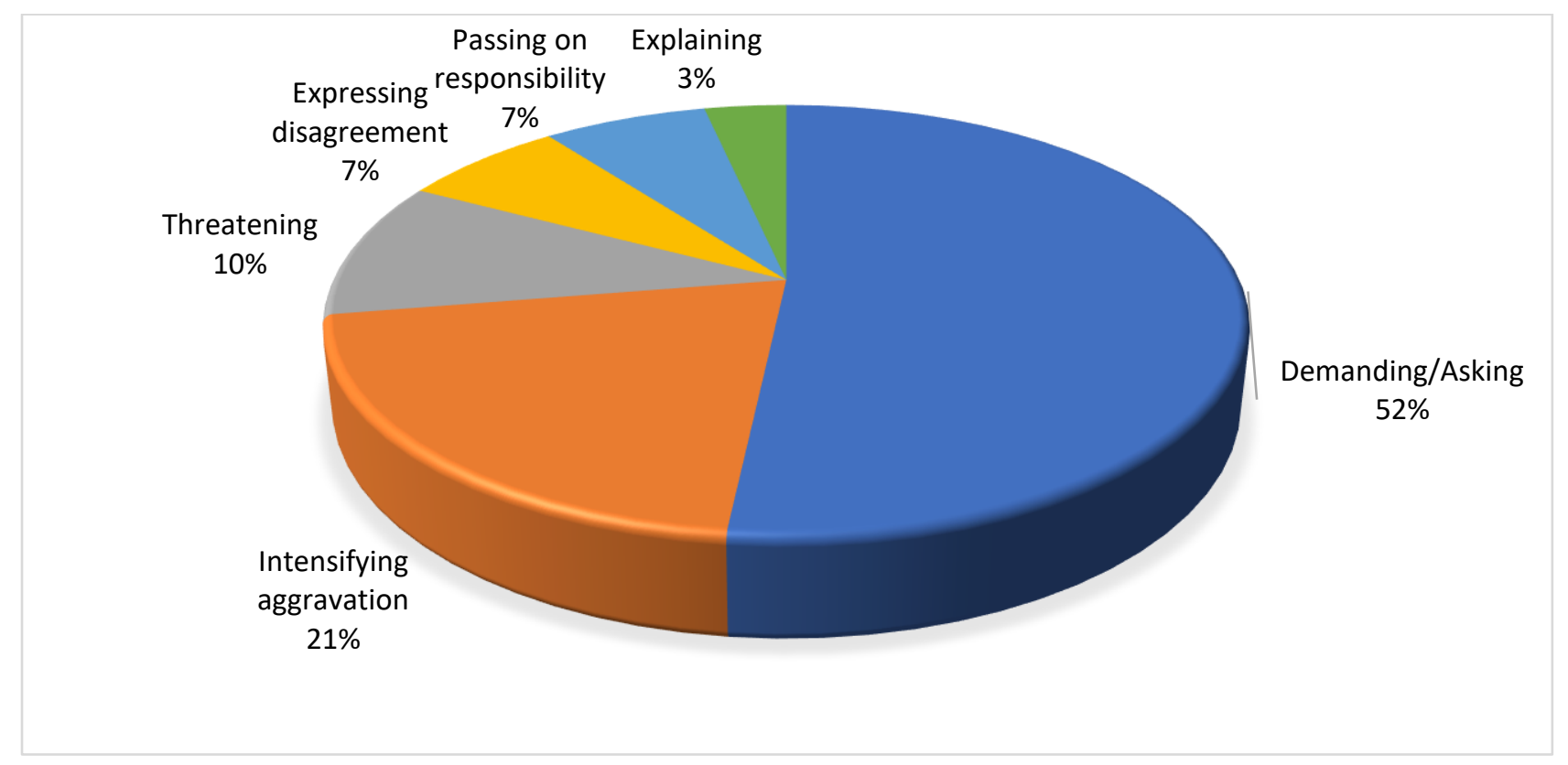

Graph 4. Percentage of aggravation devices in the police interviews

Example 19 illustrate three supportive moves from a statement being used as aggravation devices. Two of these strategies use the verb "want" in a conditional sentence (If you), 
providing hypothetical meaning to the head act. The third aggravation device is an adverb employed to describe the way in which the question is going be formulated (bluntly).

(19) If you want me to ask a question. I'll ask a question bluntly, if you want, are the children on those movies being sexually abused by adults, sexually abused?

Another type of aggravation strategy is to pass on the responsibility for the action. This is illustrated in example 20, when the offender is given the choice how he wants to handle the questions that is being asked (It is entirely up to you...how you answer the questions), followed by the officer informing the offender of his task (to get an account from you).

(20) It is entirely up to you what you're doing, how you answer the questions. That's what this is about. We're just trying to get an account from you.

Example 21 presents a threatening device which attacks the offender's face. The officer provides his views on the suspect's statement (I don't believe you, you said you can 't really surmise what's in it). This aggravation strategy is reinforced when the officer expresses his opinion about the facts (I think you know, I think you've looked)

(21) When you said you can't really surmise what's in it, I don't believe you. OK? I think you know what is on there. I think you've looked at images on there and you've watched images on there.

Another aggravation strategy uses the verbs "ask" and "tell". In example 22, "tell" is used in combination with "want" (you want to tell me), providing more weight to the illocutionary force, whilst making the request for information.

(22) So, you wanna tell me what's been happening, people have been, have people been using your account?

Most aggravation devices are hearer-oriented (20 cases) and on only three occasions, the aggravation strategies are speaker-oriented. This means that the question is formulated using the speaker as the point of reference, rather than using the hearer as the focal point for the question or statement: What I don't want to have to do, I need to know in detail and We obviously, naturally need to ask you. In these three examples, the officer uses threatening strategies to emphasise what they are planning to do and actions they will take. (One example is neither speaker nor hearer-oriented, as it is used impersonally: "The question is quite simple, isn't it?") 
During the analysis of the aggravation and mitigation strategies, other devices were found which do not fit the taxonomy categories of Tables 1 and 2 (in section 4, above). For instance, the expression to be happy is used in two different ways: one, to introduce a question and to confirm that the caution has been understood (example 23), and two, to seek approval of an action that will take place (example 24).

(23) Are you happy, do you understand the caution?

(24) Are you happy for us to do that?

The use of the deictic pronoun we in example 25 provides a different way of mitigating the illocutionary force of the head act. Instead of using the second person singular pronoun (you) to address the offender, the officer includes himself in the formulation of the question; this alleviates the imposition of the request.

(25) What sort of gap are we talking about?

In example 26, the formulation of the question is used as the subject of the statement in order to avoid personal involvement or judgement. However, in this case the impersonal element serves to increase the illocutionary force of the subsequent questions, inasmuch as it serves as a preparatory element for the formulation of the question.

(26) The question is quite simple, isn't it? Were you involved in this aggravated burglary last night?

Regarding the types of offences, a higher percentage of mitigation and aggravation strategies were found in those cases of the interviews where the offender had been arrested on suspicion of downloading and being in possession of indecent images. This is discussed in Section 6, below.

\section{Mitigation and aggravation strategies in investigative interviews}

The exploration of mitigating and aggravating strategies in the interview transcripts reveals that more mitigation than aggravation devices have been found. This confirms that mitigation is a strategy which enhances the relationship between the interlocutors (police officers and suspects) and builds rapport, in line with the engagement phase of the PEACE model, where one of the first steps is to encourage conversation by engaging with the interviewee. The type of mitigating devices found in the corpus are: question tags, impersonal constructions, verb 
tenses, modal verbs and lexical expressions such as "to be fair", "to be right". In accordance with the taxonomy proposed by Caffi (2007), illocutionary force indicating devices used for the purpose of mitigation may be classified as "hedges", given that the focus of the mitigation is on the illocution.

The findings of the current investigation, generally speaking, establishes that mitigation in police questioning is a speech act strategy whose main aim is to express feelings to the hearer (to fulfil their negative face want). However, this is not done with a view to decreasing the social distance between the interlocutors (police officer and suspect), but with the intention of increasing solidarity in the relationship between the two interactants (positive face want) in order to elicit as much information as possible. One of the specific categories of mitigating devices found in the analysis ("checking understanding") is used with a view to show solidarity and empathy between the police officer and the suspect. This hopefully leads to a more detailed account of the facts and better evidence for the criminal investigation, by adopting the PEACE framework and its interview stages, in a practical rather than rapport-building approach, although it may succeed in achieving both.

Mitigation serves to minimise the imposition of the utterance. Its main purpose is to address the interlocutor's positive face while enhancing and strengthening the relationship with the speaker. With regard to the illocutionary force of the mitigating devices often more than one strategy is used at the same time within the same instance. This result confirms Thaler's views (2012) regarding the illocutionary force of the speech act, i.e. that it is not determined by only one illocutionary force indicator, but by a cluster of linguistic devices, classified as downgraders and upgraders, according to their specific illocutionary force in each instance.

Contrary to interlocutors' tendency to use politeness as face-threat mitigation in everyday communication, mitigation strategies used as face-boosting tools constitute the norm in police interviewing. Results with regard to face-aggravation reveal that the "demanding and asking" devices (imperative verb forms and the use of "ask" and "tell") are the most common strategies. However, typical face-threatening devices (such as the use of imperatives) are also found; these attack the offenders' face and add pressure to obtain a response or reach an agreement on a statement.

The type of offence that is the target of the investigative interview is a determining factor in the use of mitigation and aggravation devices. Interviews on sensitive issues, such as sexual offences, show a higher number of devices used. Police officers' questions and statements include mitigation devices more frequently in order to attenuate the effect of what can be regarded as a delicate or compromising matter during interviews for sexual offences. 
The present investigation shows that there is no significant relationship between the use of mitigation or aggravation and actual responses by the offenders. However, future studies could explore this issue further, so as to ascertain whether the use of mitigation and aggravation gathers more elaborate responses and accounts from suspects of crime.

With regard to hearer-oriented vs. speaker-oriented devices, more hearer-oriented strategies have been found in the corpus, which is as expected, given that the questions and statements are aimed at hearers. It is important to highlight that often the aim of the speakeroriented strategies in the corpus is to bring the speaker's perspective and views to the facts provided by the suspect. According to police guidelines, in general this should not happen. At times, however, this strategy is actually used to seek solidarity and empathy with the offender.

\section{Conclusion}

The present paper has explored the mitigation and aggravation strategies used in investigative police interviews with suspects. The analysis of the instances where mitigation and aggravation strategies have been found sheds lights on a linguistic aspect which has not previously been factored into police interviewing research. As a device used in police interrogation, mitigation occurs more frequently than does aggravation. At the same time, mitigation strategies such as "checking understanding" have been found to strengthen the relationship between officers and offenders. The results of our exploration have also confirmed that the use of mitigation seems to be linked to the type of criminal offence. In sensitive offences, like sexually-related matters, mitigation strategies have been identified as the deciding factors in alleviating the illocutionary force of questions and statements. However, further research into a possible relationship between the type of offence and the use of mitigation is needed to confirm this hypothesis.

The use of a specific types of mitigation devices is connected to the individual phases of the PEACE interview model, which is part of the interview training programme for police officers. Mitigation strategies of "reporting" (you say, you said) and "seeking approval" (Is it fair to say? Am I right in saying?) are frequently used to review the facts in the "account clarification and challenge" part of the model. As stated at the beginning of the present paper, during police training, officers are briefed regarding the use of specific types of questions (open-ended rather than specific-closed). However, when performing investigative interviews, officers may modify questions through mitigation and aggravation in ways that are characteristic for the individual interviewer. Since this is likely to have an impact on the way questions and statements are phrased, it would be advisable to reflect on the use of mitigation 
and aggravation strategies during the training of police officers, in order to increasing police awareness of the impact that these linguistic devices might have on their interviewing techniques.

In the light of the findings of the present investigation, it would be very interesting to pursue contrastive research on police investigative interviews in other languages and cultures, in order to ascertain the existence there of mitigation or aggravation strategies, and whether they are used with the same purpose as has been shown in the present paper.

\section{References}

Austin, John L. 1977. How to Do Things with Words. Harvard: Harvard University Press.

Blum-Kulka, Shoshana, Juliane House and Gabriele Kasper.1989. Cross-Cultural Pragmatics, Speech Acts, Politeness. Norwood, N.J.: Ablex.

Brown, Penelope and Stephen C. Levinson. 1987. Politeness : Some Universals in Language Usage. Cambridge: Cambridge University Press.

Caffi, Claudia. 2007. Mitigation. Amsterdam: Elsevier.

Cederborg, Ann-Christin, Yael Orbach, Kathleen J Sternberg and Michael Lamb. 2000. Investigative Interviews of Child Witnesses in Sweden. Child Abuse and Neglect, 24 (10): $1355-1361$.

Culpeper, Jonathan. 2011. Impoliteness. Cambridge: Cambridge University Press.

Fisher, Ronald, R E Geiselman and D S Raymond. 1987. Critical Analysis of Police Interview Techniques. Journal of Police Science and Administration 15 (3): 177-185.

Fraser, Bruce. 1975. Hedged Performatives. In Syntax and Semantics (Vol. 3.): Speech Acts, ed. by Peter Cole and Jerry L. Morgan, 187-210. New York: Academic Press.

Fraser, Bruce. 2010. Pragmatic Competence: The Case of Hedging. New Approaches to Hedging, ed. by Gunther Kaltenböck, Wiltrud Mihatsch and Stefan Schneider,15-34. Bingley: Emerald.

Griffiths, Andy, and Rebecca Milne. 2006. Will It All End in Tiers? Police Interviews with 
Suspects in Britain, Investigative Interviewing: Rights, Research, Regulation, ed. by Tom Williamson, 167-189. New York: Willan.

Holmes, Janet. 1984. “Modifying Illocutionary Force.” Journal of Pragmatics 8:345-365.

Hübler, Axel. 1983. Understatements and Hedges in English. Amsterdam: John Benjamins.

Justice, Ministry of. 2011. "Achieving Best Evidence in Criminal Proceedings Guidance on Interviewing Victims and Witnesses, and Guidance on Using Special Measures." https://www.cps.gov.uk/sites/default/files/documents/legal_guidance/best_evidence_in criminal_proceedings.pdf

Korkman, Julia, Pekka Santtila, and N. Kenneth Sandnabba. 2006. "Dynamics of Verbal Interaction between Interviewer and Child in Interviews with Alleged Victims of Child Sexual Abuse". Scandinavian Journal of Psychology 47 (2): 109-119.

Lakoff, Robin. 1973. "Hedges: A Study in Meaning Criteria and the Logic of Fuzzy Concepts." Journal of Philosophical Logic 2:458-508.

Lamb, Michael, Irit Hershkowitz, Kathleen J. Sternberg, Barbara Boat, and Mark Everson. 1997. "Investigative Interviews of Alleged Sexual Abuse Victims with and without Anatomic Dolls". Child Abuse \& Neglect. 20(12): 1251-9.

Morris, Pauline, Steven A. Richardson, Barbara Snell Dohrenwend, and David Klein. 1965. Interviewing: Its Forms and Functions. New York: Basic Books.

Oxburgh, Gavin E., Trond Myklebust, Tim Grant, and C Meissner. 2010. "Interview and Interrogation Methods and Their Effects on Investigative Outcomes." International Journal of Speech, Language and the Law 17 (1):45-66.

Phillips, Emma, Gavin Oxburgh, Amanda Gavin, and Trond Myklebust. 2012. "Investigative Interviews with Victims of Child Sexual Abuse: The Relationship between Question Type and Investigation Relevant Information." Journal of Police and Criminal Psychology, 27(1):45-54.

Policing, College of. http://www.college.police.uk

Schneider, Stefan. 2010. "Mitigation." In Interpersonal Pragmatics, edited by Miriam A. 
Locher and Sage L. Graham, 253-69. Berlin: De Gruyter Mouton.

Searle, John R. 1976. “A Classification of Illocutionary Acts.” Language in Society 5 (1):1-23.

Searle, John R. 1979. Expression and Meaning: Studies in the Theory of Speech Acts. Cambridge: Cambridge University Press.

Thaler, Verena. 2012. "Mitigation as Modification of Illocutionary Force." Journal of Pragmatics 44 (6-7) :907-19.

\section{Acknowledgements}

I would like to thank the Constabulary for making the interview data available to our TACIT Research Team and allowing me to attend the training courses. I am very grateful to the course leader and training participants whose comments helped me contextualise my research and gave me an insightful view of police investigative interviews. I am also very grateful to Noreen Beagan for her help with the proofreading of the paper.

\section{Address for Correspondence}

Carlos de Pablos-Ortega

School of Politics, Philosophy, Language and Communication Studies

University of East Anglia

Norwich research park

Norwich NR4 7TJ

UK

c.de-pablos@uea.ac.uk

\section{Bibliographical note}

Carlos De Pablos-Ortega is Senior Lecturer in Spanish and Applied Linguistics at the University of East Anglia in Norwich. He holds a PhD in Applied Linguistics (Doctor Europeus) by Universidad Nebrija in Madrid (Spain). His research interests include: contrastive pragmatics, politeness, linguistic attitudes, and audience receptions of cultural representations in audio-visual translation. He has published in international journals (The 
Journal of Pragmatics, Pragmatics, Journal of Spanish Language Teaching, Sociocultural Pragmatics) and co-authored the book entitled Seamos pragmáticos: introducción a la pragmática española (2014) by Yale University Press. 